\title{
El dilema de la ética: entre el ser y el deber ser, la libertad y el reconocimiento del otro
}

Maribel Cuenca

Pontificia Universidad Católica del Perú

Resumen: Este artículo busca destacar dos dimensiones de la ética, concebida como un concepto que alude, inicialmente, a un modo de ser y que también refiere a un deber ser. A partir de esto se apunta a establecer algunas bases para la problematización y discusión sobre esta doble dimensión de la ética, atendiendo a algunos postulados de la filosofía antigua griega, en particular, de la ética aristotélica, y a determinadas afirmaciones de la filosofía moderna, enfatizando conceptos importantes de la moral kantiana. Con dichas herramientas, finalmente, se busca llamar la atención sobre el carácter dilemático de la ética.

Palabras clave: modo de ser, deber ser, reconocimiento del otro, libertad, con-vivencia

Abstract: This article seeks to highlight two dimensions of ethics. Understood as a concept that refers, initially, to a mode of being, and also alludes to an "ought to be". Starting from this, the aim is to establish some basis to discuss the problems deriving from this double dimension of ethics, stemming from certain ancient Greek philosophical ideas, in particular from Aristotle's ethics and certain statements from modern philosophy, emphasizing some relevant concepts of Kant's moral theory. Using said arguments, the final purpose is to call attention to the dilemma in ethics.

Keywords: mode of being, ought to be, recognition of others, freedom, co-existence 


\begin{abstract}
"El mundo redescubre hoy lo que los griegos sospechaban hace más de dos mil años: que las 'grandes palabras' provocan las 'grandes desgracias'; que el hombre, esa cosa extraña entre todas las cosas, no es aquello que debe ser superado, sino preservado, $y$ en primer lugar contra sí mismo; que el superhombre es lo que más se parece a lo inhumano; que el bien puede ser el enemigo de lo mejor; que lo racional no siempre es razonable y que la tentación de lo absoluto [...] es la fuente siempre resurgente de la desgracia humana".
\end{abstract}

Pierre Aubenque, La prudencia en Aristóteles ${ }^{49}$

¿Es la ética una "gran palabra"?, ¿por qué?Y ¿qué significa la ética?, ¿qué engloba la ética? Sin duda, la ética puede considerarse una "gran palabra" en tanto refiere a algo importantísimo en la vida de los seres humanos, una condición ineludible para la conducción y consolidación de la vida entre diversas y muchas personas. Se dice, pues, que la ética es uno de los ejes de la vida en sociedad y siempre se reitera su necesidad en las acciones de cada ser humano, en tanto estas repercuten en la vida de muchos más. De ahí que la ética tenga ganado un "sitial" en la regulación de los comportamientos, a pesar de que no deje de ser problemático describir conductas éticas, reconocerlas y asegurar su permanencia. En este sentido, la ética no es algo sencillo, no es una noción que tenga una expresión práctica segura y acabada. La ética es muy importante pero también es algo difícil de formular, de presentar como concepto y, con ello, de asegurar su permanencia, sobre todo en contextos y coyunturas tan cambiantes como las de la escena actual. Ello explica la comprensión de la ética también como algo difícil de alcanzar o como algo que se alcanza parcialmente, cuya presencia continua en la vida de las personas es un reto. De ahí que la ética se reafirme como una "gran palabra" y pueda adquirir cierto carácter solemne y trascendental; pero ello, a su vez, la puede alejar de su fuente, esto es, del acontecer cotidiano del ser humano. La "gran palabra" que puede ser la ética no debe distanciarse de aquello que la funda y sostiene, es decir, las acciones del ser humano. De lo contrario, la palabra puede devenir en un gran concepto sin expresión real, lo que atentaría contra el carácter vivencial de la ética, perdiendo de vista el sin fin de experiencias humanas que le dan sentido y la sostienen. 
Así pues, la "gran palabra" que es la ética es también una noción que parte de, y vuelve a, las experiencias humanas; en ese sentido, es una noción que nos confronta con la vida cotidiana y cambiante de los seres humanos. La ética, pues, tiene una estrecha relación con los diversos y múltiples modos de vivir de las personas, con las distintas maneras en que se expresa la vida humana, con lo que significa ser humano; $y$ eso, muchas veces, puede parecer indefinible, innombrable. La ética, en principio, nos conmina a atender al sentido de ser humano, nos conduce a comprender cómo somos sin desestimar ninguna de las maneras en que se expresa nuestro ser. En atención a esto último, en la primera parte de este artículo nos detendremos en la relación entre la ética y el ser del ser humano.

\section{\$ 1. El ser del ser humano: vivir en una comunidad junto a otros}

Nacer en un mundo implica para el ser humano, entre varias cosas, estar con otros y, a partir de esto, aprender a vivir con estos otros asumiendo dicha condición. Estos otros son otros seres humanos que también tienen que aprender y, por supuesto, asumir su situación. Así pues, el ser humano se va reconociendo como un ser que, en términos generales, forma parte de un todo que reúne a otros individuos como él, que viven junto a él, de manera que el vivir humano se presenta como un con-vivir, como un estar con otros $y$, por tanto, como un aprender a vivir con otros. De este escenario parte la ética y en él se desarrolla. El origen del término "ética" da luces al respecto.

El término que está en los orígenes de lo que hoy llamamos ética es el griego ethos, palabra cuya carga semántica se relaciona estrechamente con la condición de con-vivencia de la vida humana y con lo que resulta de esta. Así, el ethos nombra el lugar o morada (que se habita) $y$, consecuentemente, las costumbres, creencias y hábitos (que se adoptan), en suma, un modo de ser (que se muestra). Dicha idea, junto a muchas más, fue rescatada posteriormente por los romanos y referida bajo su lengua. Así, el ethos griego fue el mos, moris, mores latino, es decir, con este último término los romanos nombraron la misma noción de con-vivencia humana y sus manifestaciones. De este último término latino derivó la moral, siempre con la intención de traducir, en principio, la noción antes referida. De modo que podemos afirmar que la ética y la moral son términos etimológicamente equivalentes y, en función de ello, 
podemos tratarlos indistintamente ${ }^{50}$. Eso es lo que trataremos de hacer en este artículo, a pesar de que sabemos que la ética y la moral no se entienden hoy en día de la misma manera, pues se han planteado (y se plantean) distintos criterios para diferenciarlas. Pero redundar en esto último nos alejaría de los objetivos del presente texto, por ello no nos detendremos en la diferencia referida, salvo que sea estrictamente necesario en atención a lo que tratamos de transmitir en este escrito.

La importancia del ethos repercutió en la relevancia del escenario de convivencia que permitió hacerlo más visible y regularlo. Para los griegos, ese escenario, por excelencia, fue la polis o comunidad (también traducido como ciudad), en donde el ser humano se realizaba a partir de la interacción libre. Tal comunidad era mucho más que un territorio, era el espacio que hacía posible la relación con el otro y la realización de determinados fines. Vivir en comunidad era mucho más que ocupar un lugar en el espacio común, vivir en la polis era estar en un escenario de gran interacción, sabiendo que la relación con el otro era fundamental para vivir bien ${ }^{51}$. El escenario que hace posible la interacción humana es lo que, también, hace posible el surgimiento y la afirmación del ethos, pues un modo de vivir o una forma de ser está condicionada a una dinámica en la que los individuos actúan relacionándose entre sí. Sin duda, el aprender a vivir por parte de una persona descansa en un factor individual, esto es, depende de las actitudes y fines de la persona en sí, pero también está en función de su relación con otros semejantes y también diferentes, con los cuales forma un todo. Este todo era, para los griegos, definitivamente la polis, pero también podría equipararse, ya en la modernidad, a la sociedad o a la noción de colectivo que en la escena actual tiene cada vez más fuerza. El común denominador de estos escenarios es el hecho de que se vive con otros $y$, en esta con-vivencia, en mayor o menor medida, se aprende.

Si el filósofo griego Aristóteles concebía al ser humano como un animal político, es decir, como un ser de la polis (comunidad) y para la polis, nosotros podemos decir hoy en día, salvando las distancias, que el ser humano es un ser de grupos, que siempre está formando y/o participando en grupos de

50 Cf. Giusti, Miguel, “El sentido de la ética”, en: Giusti, Miguel y Fidel Tubino (eds.), Debates de la ética contemporánea, Lima: Fondo Editorial de la PUCP, 2007, pp. 18-2I.

345 Cf. Aristóteles, Política, Madrid: Alianza Editorial, 2000, I28Ia, pp. I34-I35. 
distinta magnitud y de diverso carácter. Gracias a estos grupos, en sus relaciones con los otros, el individuo aprende sin que, por cierto, este aprendizaje esté exento de dificultades y conflictos: "En nuestras vidas normales, nos consideramos miembros de una variedad de grupos; pertenecemos a todos ellos. La ciudadanía, la residencia, el origen geográfico, el género, la clase, la política, la profesión, el empleo, los hábitos alimentarios, los intereses deportivos, el gusto musical, los compromisos sociales, entre otros aspectos de una persona, la hacen miembro de una variedad de grupos. Cada una de estas colectividades, a las que esta persona pertenece en forma simultánea, le confiere una identidad particular" ${ }^{52}$.

Somos seres que estamos con otros formando grupos, grupos de diversa y múltiple índole. Estamos con otros y también nos juntamos a otros, y en ese co-estar incorporamos diversas cosas, desde hábitos y prácticas comunes, hasta supuestos y expectativas determinadas. Vivir con otros en un grupo contribuye a adoptar una manera de ser, identificando cosas, asumiendo significados y afirmando juicios de valor. Como pensaban los antiguos griegos, un ethos se adopta y adquiere más sentido gracias a la vida con otros, pues esto condiciona la afirmación de significados comunes, la toma de distancia respecto de determinadas ideas y la consecución de ciertos fines. En suma, el grupo o el colectivo ayuda al individuo a formar una identidad que le permite situarse mejor en la realidad. Con-viviendo con otros planteamos y validamos creencias, prejuicios e ideales, los que, en cierto grado, nos sostienen en la vida, dirigiendo nuestro andar cotidiano $y$ evidenciando que hay muchas $y$ diversas aproximaciones a las cosas, y que ellas son necesarias para desenvolvernos bien en la vida. Pero ser parte de la con-vivencia con otros no solo nos otorga unas cosas, también nos exige otras poniéndonos condiciones. De alguna forma y en cierta medida, vivir con otros supone aceptar acuerdos y acatar directrices, lo que no ha sido, es, ni será sencillo, porque ello expresa restricciones a los comportamientos de los individuos que, por lo menos, pueden incomodar. Desde esta perspectiva, vivir bien con otros descansa también en saber vivir bajo las exigencias de esta vida. Con todo, no debemos olvidar que esta con-vivencia, al formarnos de cierta manera, ya nos está ayudando a situarnos mejor en la realidad, pues ella nos permite tener, en principio, un 
enfoque de las cosas, una manera de ser y de ver las cosas: “(...) una moral en este sentido es un sistema de exigencias recíprocas que están expresadas en un tipo de oraciones de deber. La obligación expresada en estas oraciones se basa en los sentimientos de indignación y culpa. Cada sistema definido así tiene un concepto de buena persona" ${ }^{53}$.

La vida con los otros da forma, en principio, a una ética, a una moral ${ }^{54}$ que se asienta en supuestos y enfatiza expectativas; un modo de ser que, en cierto grado, nos forma y nos compromete; una manera de vivir que comprende sentidos compartidos, sentimientos aceptados y exigencias siempre señaladas. Asumimos, con los otros, significados que, al inicio, poco discutimos; comprendemos que está bien sentir ciertas cosas y mal sentir otras; sabemos que la comunidad, la sociedad o el colectivo ${ }^{55}$ nos traza ciertos caminos esperando que los sigamos. Pero, al tratarse la ética de una manera de ser, esta consiste en un modo de vivir que, estando asentado en determinados supuestos, no es estático, pues es un modo de vivir de individuos que así como adoptan ideas, también las replantean, lo cual imprime dinamismo a esa manera de ser.

Con todo, al comenzar a vivir, no decidimos cómo vivir, pues nacemos en un contexto que nos forma y que, recién un poco más adelante, también nos muestra la posibilidad de disentir. Pero para disentir hay que, primero, comprender supuestos y expectativas, conocer comprensiones de lo bueno que, en cierto grado, incorporamos y, hasta cierto punto, van asentándose en nuestra vida cotidiana. Una vez iniciado este proceso, podemos reconocernos o no en tales ideales y, a partir de ahí, reafirmar creencias o tomar distancia respecto de las mismas. Pero disentir y tomar distancia supone siempre partir de algo, de un modo de ser y de ver las cosas que, en principio, nos forma:

53 Tugendhat, Ernst, Problemas, Barcelona: Gedisa, 2002, p. 123.

54 Recordemos que estamos tratando indistintamente a la ética y a la moral, dada su equivalencia etimológica.

55 Usamos estos tres términos debido a que son los que más se emplean para aludir a aquellos grupos que congregan y determinan a los seres humanos. Sin embargo, hay que acotar que la definición de cada una de tales palabras, indicando la cercanía y distancia entre sus significados, puede dar lugar a una larga y profunda discusión. No habiendo espacio en este texto para tal discusión, nos remitimos a significados generales (no exentos de la problematización respectiva): la sociedad como un grupo que reúne a seres humanos otorgándoles cosas y exigiéndoles otras, bajo la lógica del estado moderno; la comunidad como un grupo que congrega seres humanos bajo criterios histórico-culturales; y el colectivo como un grupo conformado por seres humanos que comparten perspectivas e intereses y que tienen solicitudes a partir de estos. 
"Soy hijo o hija de alguien, primo o tío de alguien más, ciudadano de esta o aquella ciudad, miembro de este o aquel gremio o profesión; pertenezco a este clan, esta tribu, esta nación. De ahí que lo que sea bueno para mí deba ser bueno para quien habite esos papeles. Como tal, heredo del pasado de mi familia, mi ciudad, mi tribu, mi nación, una variedad de deberes, herencias, expectativas correctas y obligaciones. Ellas constituyen los datos previos de mi vida, mi punto de partida moral. Confieren en parte a mi vida su propia particularidad moral" 56 .

Hay un punto de partida moral en la vida de todo ser humano que responde a su condición de ser de comunidad, de sociedad o de un colectivo (o de los tres a la vez). Así comienza a perfilarse un modo de ser peculiar, una particularidad moral que siempre estará en constante formación, pues las expectativas e ideales que acogemos no son los mismos, ya que los referentes y guías que nos acompañan se replantean o los percibimos de distinta manera de acuerdo al tiempo. Entonces, ser de un modo consiste en situarse en un contexto particular y ver las cosas de una determinada manera, describiéndolas, contemplándolas y evaluándolas según ciertos criterios, evidenciando así prioridades y valoraciones. Pero los modos de ser no son eternos, en cierto grado, siempre están cambiando en atención a las relaciones que entablamos con los otros, a los grupos que formamos y a las cosas en las que vamos creyendo. Ello determina el carácter cambiante de la ética en tanto modo de ser.

Este carácter cambiante de un modo de ser se sustenta en la respuesta del individuo a los mensajes que le transmite su contexto. Estos mensajes comprenden, entre otras cosas, lo que se considera bueno, lo que se cree malo, lo que se espera de cada individuo y lo que se rechaza en un comportamiento. El ser humano siempre responde a esto de diversas maneras: desde la respuesta más asertiva respecto de lo enseñado y estipulado en una comunidad, una sociedad o un colectivo, hasta la respuesta más escéptica respecto de lo mismo. Pues siendo los individuos diferentes, la recepción de los mensajes de su contexto varía de acuerdo a factores como el tiempo, la actitud, el interés, la reflexión, etc. La recepción y asimilación de dichos mensajes se da de muchas maneras, asintiendo plenamente a estos, mostrando desconfianza con

56 Maclntyre, Alasdair, Tras la virtud, Barcelona: Crítica, 1988, p. 271. 
respecto a los mismos o criticándolos radicalmente. Con todo, tales mensajes siempre están ahí, su presencia es permanente en tanto pilares de una vida en comunidad, más allá de su aceptación o rechazo por parte del individuo. De hecho, la identidad que anima a un grupo determina en diversos grados a sus integrantes, más allá de que uno de estos se rebele contra ella, pues incluso la crítica contundente de los supuestos, expectativas y fines de la comunidad, la sociedad o el colectivo en el que nos hemos formado es una forma de expresarlos, es una manera de actualizarlos y, así, mostrar su vigencia ${ }^{57}$.

El conjunto de supuestos e ideales que determina a una totalidad de personas está asentado gracias a muchos seres humanos que los acatan y que sujetan sus vidas a estos. Evidentemente, así como hay individuos críticos respecto de los referentes que gobiernan su contexto, también hay individuos que expresamente quieren seguir formando parte de este todo en el que están, enfatizando su modo de ser y su comprensión de lo bueno o de lo que significa ser bueno. De ahí que acojan normas comunes y se exijan recíprocamente su cumplimiento, repotenciando y consolidando maneras comunes de razonar y de sentir indignación o vergüenza, por ejemplo ${ }^{58}$. Hay un modo de ser que, en principio, se conserva, modo de ser que siempre puede cambiar y ser replanteando, pero esto supone un proceso largo y complejo del cual no son responsables unos cuantos individuos.

El modo de ser que sostiene a una comunidad, a una sociedad o a un colectivo es un referente ineludible para los seres humanos que con-viven; un referente que, en principio, permite un con-vivir, pero que no está libre de críticas y, consecuentemente, de correcciones y de replanteamientos. Como pensaba Aristóteles, “[...] el carácter ( $\tilde{\eta} \vartheta$ os) [ethos] no es más que un conjunto de hábitos $\left({ }^{\prime} 9 \eta\right)$ [nota a pie omitida] nunca totalmente asegurados si son buenos, ni totalmente irrevocables si son malos" ${ }^{59}$. En todo caso, el ethos es un modo de ser que comprende supuestos, ideales y hábitos que evidencian valoraciones, es decir, cosas que valoran la mayoría de individuos miembros de un determinado grupo en cierto tiempo y lugar. Pero ello no se identifica

57 Cf. ibid., p. 272.

58 Cf. Tugendhat, Ernst, Lecciones de ética, Barcelona: Gedisa, 1997, p. 59.

59 Citado en: Aubenque, Pierre, op. cit., p. 150. 
con "lo indefectiblemente bueno" 60 ni se distancia de "lo indiscutiblemente malo", pues finalmente el ethos se sostiene en valoraciones (que dan lugar a prescripciones) que dependen de seres humanos. Los muchos y diversos seres humanos miembros de una comunidad, de una sociedad o de un colectivo son los que se identifican, o no, con las expectativas y prácticas del contexto en el que viven $y$, por ende, son los que deciden su vigencia. El sostén de un ethos son individuos que sienten, piensan y actúan; individuos que reciben mensajes que entienden o tratan de entender y que, en tanto individuos libres, son capaces de valorar o no y, así, de actuar o no conforme a ellos.

La condición de ser libre de todo individuo hace posible la respuesta del mismo a su situación y a sus circunstancias, sabiendo que, en principio, no tiene poder sobre un mundo cambiante e imprevisible ante el que, sin embargo, puede y tiene que deliberar y escoger. En este punto, continuando con Aristóteles, adquiere relevancia la prudencia, en tanto el ser humano está obligado a deliberar en un mundo difícil, respondiendo a este, pensando, planeando y consecuentemente actuando. La naturaleza compleja de su situación invita al individuo a responder, esto es, a actuar evidenciando su libertad ${ }^{61}$. De esta manera, el ser humano se muestra libre y esta condición le permite pensar y planear, en principio, su vida. En tanto siente de diversas maneras, piensa y cree en diferentes cosas e interpreta según sus criterios y lo que valora, el ser humano comprende de múltiples formas lo bueno, lo mejor para él y, a partir de eso, va en su búsqueda. Ello no expresa un trayecto sencillo y fluido, pues, como sabemos, todo se da bajo un ethos, bajo un modo de ser con el que podemos comulgar o no en distintos grados.

El ser humano es un ser que quiere estar bien y que hace cosas con el fin de estar bien. Con el paso de los años, el individuo se puede dar cuenta de lo que quiere y no quiere, de qué significa para él estar bien o ser feliz, y conforme a ello tratar de actuar en su comunidad, sociedad o colectivo. En otras palabras, a partir de la comprensión de su situación, de sus intereses y de la importancia de estar bien, el individuo va intentando conducir su libertad. Así adquiere importancia y justifica su lugar la libertad en la ética, en tanto condición de la

60 "Lo indefectiblemente bueno" no existe, dado el carácter histórico, cultural y temporal de la ética en tanto modo de ser.

6I Cf. ibid., p. III. 
vida humana que hace posible la toma de decisiones y elecciones, y acompaña la vida de todo individuo a partir de su disposición a ser feliz y su esfuerzo por alcanzar esto.

De este modo adquiere realce preguntar más por el cómo se es libre antes que el qué es ser libre. Pues lo primero nos exige situarnos rápidamente en contexto, es decir, abordar la libertad "en acto" y ver sus posibilidades en el acontecer de una vida. Esto significa que, sin dejar de ser importante la reflexión y discusión en torno a la libertad en sí, la reflexión sobre cómo se es libre o cómo se puede ser libre en la vida resulta ser más significativa, porque nos confronta inevitablemente con realidades, contextos, historias, tiempos y modos de ser. Es decir, nos confronta con cosas que realmente nos interpelan y que nos piden respuestas, directa o indirectamente, en el actuar cotidiano. Por todo ello, el ser libre entra en escena en la reflexión sobre la ética, pues el individuo se sabe libre y quiere seguir afirmando su libertad en su vida. Pero todo esto se da en el contexto de un ser que vive en una comunidad, una sociedad o un colectivo que, como sabemos, lo determina. Sin embargo, tal sigue siendo un ser libre que quiere hacer cosas porque quiere estar bien, un ser que quiere conducirse libremente para estar bien, apelando a diversos medios para alcanzar su bienestar. Así se hace evidente la complejidad del ejercicio de la libertad, las distintas maneras de ser libre, los diferentes modos de buscar lo mejor para cada uno, las muchas formas de actuar libremente. Este actuar libre es, finalmente, un inter-actuar libre que, como tal, exige cuidarse, ya que aun cuando sean legítimos los diversos modos de buscar lo mejor para cada uno (ser feliz), dichos modos, a la larga, tienen repercusiones que las siente el contexto en el que estamos y, en concreto, las demás personas que también están en él. No es sencillo vivir de manera libre sabiendo que hay una ética, en tanto modo de ser, que nos determina, y otros como nosotros que nos acompañan e interpelan, a la vez, en la con-vivencia.

\section{§ 2. El deber ser del ser humano: ser en atención a los otros}

En esta segunda parte del artículo recogemos las últimas reflexiones sobre la ética, la libertad y la relación entre estas, y apuntamos a ciertas dificultades que trae la apuesta por un vivir libre en un escenario marcado, en cierto grado, por un modo de ser y que tiene como eje a la vida con los otros, lo 
que trae consigo obligaciones para el ser humano. Si entendiésemos la convivencia que determina al ser humano como la pertenencia a un escenario conformado por varios y diversos individuos que viven únicamente uno al lado del otro, formando parte de un mismo espacio y pasando por un mismo tiempo, tendríamos una descripción artificial de la condición humana que, por ello, no mostraría en su real dimensión las dificultades y los retos que la vida con el otro presenta. Sin duda, la vida propiamente humana va mucho más allá de una suerte de yuxtaposición de individuos, pues ella se asienta y despliega a partir del contacto entre esos individuos y todo lo que ello puede generar. Así pues, lo determinante en la vida del ser humano en la sociedad, la comunidad o el colectivo no es simplemente el estar con otros, sino sobre todo lo que exige ese estar con otros; esto es, las condiciones que trae la inevitable relación con los otros.

La relación con el otro (y cómo esta se pueda expresar y diversificar) es un factor crucial en la vida del ser humano, pues es lo que le otorga, en buen grado, dinamismo al acontecer cotidiano del individuo, al confrontarlo con la necesidad de entablar vínculos con otros como él y con la obligación de responder a dichos vínculos de determinada manera. En ello descansa la con-vivencia humana, en un hecho ineludible, en una cuestión práctica, esto es, en cómo vivir relacionándome con los otros. La vida del ser humano adquiere sentido en la condición permanente de estar viviendo con los otros y en cómo se entiende y asume tal condición. En términos generales, no elegimos formar parte de ciertos grupos, estar en esta sociedad o en esta comunidad, pero ya estando en este escenario de vida con otros, tendría que evidenciarse, paulatinamente, todo lo que esta condición posibilita. Vivir relacionándonos con otros hace posible, ante todo, situarnos en el mundo; eso es lo básico e inicial: cómo el vínculo que entablo con otros diversos ayuda a comprender mejor la realidad en la que estoy, en sus distintas dimensiones $y$ desde diferentes ángulos. Antes que desarrollar una relación particular con el otro, acompañada de determinados compromisos, lo que la con-vivencia me otorga es la oportunidad de abordar con el otro la realidad que nos ha tocado vivir, tratando de comprenderla y de situarnos mejor en ella. Pues vivir con el otro es, inicialmente, comprender que se comparte un espacio y una vida, comprender que se forma parte de una realidad en común que nos estimula e interroga, una realidad que llama nuestra atención: "Sólo [se] puede ver y experimentar el mundo tal como éste es 'realmente' al entenderlo como algo 
que es común a muchos, que yace entre ellos, que los separa y los une, que se muestra distinto a cada uno de ellos y que, por este motivo, únicamente es comprensible en la medida en que muchos, hablando entre sí sobre él, intercambian sus perspectivas. Solamente en la libertad del conversar surge en su objetividad visible desde todos lados el mundo del que se habla. Vivir en un mundo real y hablar sobre él con otros son en el fondo lo mismo (...)"62.

Situarse y comprender mejor el mundo en el que se está es, en un importante grado, saber de los otros que viven con nosotros y de lo que la relación con ellos nos otorga. Situarse mejor en la realidad es comprender mejor a los otros que también están en ella, aprendiendo a darles su lugar. Así pues, el vínculo con el otro aparece como algo crucial en el desarrollo de la vida de todo individuo. No se trata de elegir relacionarme con las demás personas que están en mi realidad, sino de comprender la necesidad de dicha relación, siempre y cuando quiera verdaderamente comprender mi realidad y responder a las situaciones que en esta se presentan. No se trata, pues, de tener consideraciones especiales con los demás, sino de entender quiénes son los demás, qué traen consigo y qué buscan, dado el lugar que tienen en el mundo y, por ende, dada la relevancia que tienen también para mi vida. La cuestión inicial no es buscar la amistad, sino apuntar a la comunicación como vía imprescindible para entender mejor en dónde estamos. En ese sentido, es importante reconocer al otro, esto es, entender la situación de las demás personas que también forman parte de una realidad, entender que responden a la misma condición a la que yo respondo (vivir con otros), que son también estimulados por un contexto, que tienen preguntas, que buscan respuestas, que creen en algo y que lo afirman, y que quieren cosas.

El otro es un ser humano como yo, interpelado por su entorno, con ideales y expectativas, $y$ con cosas que decir. $Y$ en tanto el otro habita también mis espacios y con-vive conmigo, se parece a mí, es como yo: "Desde el comienzo, cuando nos paramos a pensar, algo que parece total y radicalmente solitario, estamos con los otros, y muchas veces (para bien y para mal) descubrimos que somos los otros. Aunque en muchos momentos parezcamos estar solos, e incluso abandonados -decimos-, estamos hechos de las historias de los 
otros, de lo que ellos han tejido, y ellos están en el horizonte de todo lo que nos proponemos" 63 . Por eso el otro se parece a mí, por eso los seres humanos nos parecemos, en tanto individuos que con-viven portando supuestos, creencias, intereses y metas, en suma, portando una historia. Ello sustenta la relación de respeto que debo al otro, su reconocimiento, más allá de la cercanía temporal o espacial de este, más allá de que este sea miembro permanente de mis grupos, más allá de que este sea alguien a quien vea cotidianamente y comparta generalmente mis diversas opiniones. El otro es como yo, un ser humano que conforma una sociedad, una comunidad o un colectivo (o los tres a la vez) y que, por ello, recibe mensajes y está sujeto a ciertas presiones.

El otro también sabe de ética, en tanto percibe modos de ser o maneras de vivir que le transmite su realidad en general y sus grupos en particular. El otro también puede entender, por tanto, las dificultades que implica la convivencia, lo difícil que muchas veces es vivir entre individuos tan parecidos y tan diferentes. El otro es muchos otros diversos, diferentes y múltiples seres humanos que, en principio, se muestran originales y particulares. Todo individuo en su realidad y lugar de con-vivencia es un otro para los demás, esto es, un ser "extraño", distinto, que nos confronta y con el que hay que relacionarse. Por eso, inicialmente, esta relación puede ser difícil, porque no se sabe ante quién se está, quién nos hace frente, pero, con todo, hay que vincularse con este de algún modo. Y, en principio, nadie dirige o debe dirigir la relación, esta solo se da en tanto todos somos seres humanos únicos y otros a la vez, es decir, en tanto todos estamos en las mismas condiciones. De ahí que la mostración de cada individuo sea imprevisible e ilimitada, esto es, que cada individuo se pueda mostrar de inimaginables e innumerables maneras, que cada individuo presente distintos modos de ser. Solo sobre esa base cambiante, dinámica e irregular que conforman los seres humanos distintos se puede intentar concebir al otro, es decir, intentar definirlo para formar un concepto de él. La mostración del ser humano es -o debe ser- previa a su concepción; primero, los individuos se muestran de diversas maneras y, luego, se intenta definirlos de distintos modos, no al revés. En ello se sustenta el reconocimiento. Este es, pues, la relación respetuosa con el otro, el vínculo cuidadoso con el otro que no es, en principio, un individuo cualquiera, sino

63 Thiebaut, Carlos, Invitación a la filosofía. Un modo de pensar el mundo y la vida, Bogotá: Siglo del Hombre/PUJ, 2008, p. 160. 
un ser humano que siente, piensa, cree y habla de una determinada manera en atención a lo que lo moviliza en la vida. El otro es un ser humano que, por ello, espera ser atendido y escuchado y, en ese sentido, reconocido, más allá de que su visión y proyecto de vida genere simpatía y gane adeptos o, por el contrario, sea cuestionado y rechazado.

Hay razones, pues, que sustentan la importancia del otro, este otro que es mucho más que materia ocupando un lugar en un espacio común, este otro que es una persona que, con su historia, intereses y objetivos, configura una realidad que también es nuestra, que es de muchos. La realidad que conformamos, el escenario en el que actuamos, se hace significativo gracias al aporte de muchos, pues solo sus experiencias y perspectivas hacen posible que el sentido de objetos y asuntos diversos se mantenga y que, así, ello nos congregue, nos reúna: "Bajo las condiciones de un mundo común, la realidad no está garantizada principalmente por la 'naturaleza común' de todos los hombres que la constituyen, sino más bien por el hecho de que, a pesar de las diferencias de posición y la resultante variedad de perspectivas, todos están interesados por el mismo objeto. Si la identidad del objeto [sea este un aparato electrónico de última generación o un conflicto social no resuelto] deja de discernirse, ninguna naturaleza común de los hombres, y menos aún el no natural conformismo de una sociedad de masas, puede evitar la destrucción del mundo común, precedida por lo general de la destrucción de los muchos aspectos en que se presenta a la pluralidad humana"64.

La comprensión de esta importancia del otro implica, o debe implicar, un comportamiento consecuente, esto es, un comportamiento que no desatienda a los demás, que no los pierda de vista. Esto significa, en general, un comportamiento siempre consciente de la presencia de los otros y, en concreto, un actuar cotidiano que siempre suponga el respeto a las demás personas, en tanto estas conforman también mi espacio, son testigos de mis actos $y$, eventualmente, seres humanos que pueden verse afectados por ellos. De esta manera, el otro "altera" mi desempeño en la realidad, pues aparece como un factor que tiene que determinar, en cierta medida, mi forma de actuar, si soy consciente de mi situación de con-vivencia. En cierta forma, pues, mi

64 Arendt, Hannah, La condición humana, Barcelona/Buenos Aires/México D.F.: Paidós, 1996, pp. 66-67. 
proceder es con respecto al otro, mi actuar se da con respecto a los demás. $\mathrm{El}$ otro que vive en mi espacio tiene un rol importante que, al influir en mi comportamiento, a la larga está influyendo en mi actuar libre y en mi modo de ser. En este sentido, el otro expresa la necesidad de límites para todo actuar, la exigencia de regular el ejercicio de libertad propio y legítimo de todo ser humano, la obligación de siempre situar la acción propia en un contexto y circunstancias particulares. Así pues, la obligación que, en determinado grado, acompaña a la performance humana no es gratuita; además, conduce a replantear la comprensión de la libertad, influye en su ejercicio e invita a reconsiderar maneras usuales de actuar en la vida (finalmente, modos de ser). La obligación se hace entonces presente como un factor influyente en la ética, en tanto esta se entiende como modo de ser.

Habíamos afirmado, en la primera parte de este artículo, que la ética es un modo de ser relativo a un todo que reúne y determina a seres humanos que se encuentran en él; en esa línea, habíamos destacado el vínculo estrecho entre la ética y los distintos grupos que cada ser humano siempre está conformando, sean estos comunidades, colectivos o sociedades. Se afirmó que la ética, en tanto modo de ser, se asentaba en primer lugar en la condición humana de vivir junto a otros. Pero explorando esa condición humana, se ha hecho necesario precisar que ese vivir junto a otros es un vivir con otros, lo cual enfatiza a la obligación como un factor siempre presente al perfilar la ética. Una obligación no per se, sino una obligación con los otros que viven conmigo, en atención a diferentes y múltiples vínculos. Por ello, siendo la ética un modo de ser, no solo es un modo de ser a secas, sino un modo de ser siempre sujeto a mensajes prescriptivos, a obligaciones que siempre se recuerdan, a líneas de acción que constantemente se realzan. Todo ello apunta a moldear un comportamiento, y tales regulaciones se originan y sustentan, otra vez, en una realidad determinada, en un particular escenario de con-vivencia, en un contexto que da sentido a la vida de muchos; esto es, en un modo de ser (vivir). Es claro que en este modo de ser es legítimo actuar libremente, y también debería ser claro que se tiene que atender a los otros en nuestro actuar. Así pues, ser de una manera es complejo, es decir, la ética es compleja, pues al tiempo que afirma una manera de vivir libre, también enfatiza limitaciones y obligaciones para ella. De ahí que se pueda afirmar que la ética, en tanto modo de ser, es, a la vez, un deber ser. Este deber ser se funda, en principio, en nuestra comprensión del lugar de cada una de las personas en nuestra realidad, en 
razón de su condición de ser humano. Y este deber ser se puede diversificar y orientar en atención al aspecto, dimensión o cualidad humana que se considere preponderante y que, por ende, se quiera destacar. Así pues, la carga de obligatoriedad que se identifica en la ética y que descansa en la vida con el otro se ha entendido y se entiende, se ha orientado y se orienta de más de una manera. Así, en su reflexión sobre la moral, el filósofo alemán Immanuel Kant afirma que la conciencia moral está sujeta a mandatos internos categóricos, y una manera en la que entiende y formula tales mandatos es la siguiente: "(...) obra de tal modo que uses la humanidad, tanto en tu persona como en la persona de cualquier otro, siempre como un fin al mismo tiempo y nunca simplemente como un medio" 65 . El actuar moral, según Kant, está sujeto a una orden de la conciencia que se debe acatar, pues dicho imperativo apunta a acciones cuya validez descansa en sí mismas y no en las consecuencias que puedan acarrear, pues lo más importante es el móvil racional y puro de tales acciones. De ahí que sea obligatorio, al actuar, atender al otro que forma parte de mi realidad, prioritariamente, como un fin en sí mismo, es decir, como un individuo a respetar en tanto sujeto racional. Ello sustenta suficientemente el vínculo moral con el otro.

Para Kant, el otro es, ante todo, un sujeto racional y ello es fundamento suficiente para rechazar su mera instrumentalización, para destacar su importancia como un fin en sí y para prescribir un trato acorde con el carácter que ostenta. A partir de esto se puede ver en Kant un referente sugerente e interesante para la reflexión en torno a la relación con el otro y bajo qué términos se concibe el respeto a este, esto es, su reconocimiento. Lo que se puede desprender del referente kantiano es que el otro es, ante todo, un sujeto que razona y que, como tal, merece un trato acorde con su condición. Lo determinante es, en principio, no cómo o qué razona, sino que razona; lo preponderante es la capacidad (racional) que posee, y las propiedades y posibilidades que ella le otorga. A la larga, se puede desprender de lo anterior que el sujeto es, en tanto racional, un sujeto con facultades importantes y determinantes para la organización de la vida en su realidad. Es decir, el sujeto racional es una persona con derechos cuyo respeto debe regular las relaciones entre los individuos que comparten y conforman un todo: "El derecho es la

65 Kant, Immanuel, Fundamentación de la metafísica de las costumbres, Madrid: Tecnos, 2005, p. 117. 
limitación de la libertad de cada uno a la condición de su concordancia con la libertad de todos, en tanto que esta concordancia sea posible según una ley universal; $y$ el derecho público es el conjunto de leyes externas que hacen posible tal concordancia sin excepción. Ahora bien: dado que toda limitación de la libertad por parte del arbitrio de otro se llama coacción, resulta que la constitución civil es una relación de hombres libres que [...] se hallan, no obstante, bajo leyes coactivas; y esto porque así lo quiere la razón misma, y ciertamente la razón pura, que legisla a priori sin tomar en cuenta ningún fin empírico [...]”66. De esta manera, el otro con el que se vive sigue marcando, en un importante grado, la pauta de la con-vivencia, en tanto persona libre portadora de derechos. En esta línea argumentativa, también encontramos pensadores como John Stuart Mill, quien al reflexionar sobre el actuar libre de la persona en sociedad, afirma que se puede justificar la restricción de la libertad de esta si sus acciones amenazan con hacer daño a otra persona, es decir, si sus acciones amenazan con atentar contra los derechos de otro ${ }^{67}$.

Así pues, se tiene una lectura del lugar y del papel del otro en la vida en sociedad que se funda en la concepción de la persona como sujeto racional a ser tratado como fin en sí mismo, y su desarrollo da pie a interpretaciones más puntuales según las cuales la persona es un sujeto de derechos, siendo el respeto a estos lo que regula, o debe regular, la acción libre en el espacio social. Finalmente, el límite sigue siendo el otro, los límites los siguen marcando las otras personas que viven conmigo. Pero el otro no solo es un sujeto racional, recordemos que el otro es, ante todo, un ser humano y que, como tal, tiene distintos rostros, presenta diversas dimensiones, en suma, es de diferentes maneras. Ello debería ser evidente en atención a lo que se subrayó en la primera parte de este artículo: somos seres de grupos, siempre somos parte de comunidades, colectivos o sociedades. Y ello no como producto, necesariamente, de una militancia formal y plenamente consciente en un grupo " $x$ ”, sino como resultado de nuestra condición de con-vivencia y de las respuestas que damos a esta situación que nos determina. Consciente $o$ inconscientemente, directa o indirectamente, conformamos grupos, yesto trae desenlaces diversos: afirmamos más a algunos grupos, dudamos y cuestionamos a otros o nos alejamos definitivamente de determinados espacios sociales.

66 Kant, Immanuel, Teoría y práctica, Madrid: Tecnos, 20II, 289/290, p. 26.

67 Cf. Wolff, Jonathan, Filosofía política. Una introducción, Barcelona: Ariel, 200I, p. I33. 
Con todo, estas sociedades, comunidades o colectivos comprenden discursos, presentan modos de ser que no necesariamente pasan desapercibidos, más allá de que comulguemos con ellos o los rechacemos. En ese sentido, los grupos forman a las personas, otorgan significados y perspectivas (que acogemos, que simplemente atendemos o que rechazamos) y así contribuyen a situar a los individuos en el mundo, dándoles contenidos y sustento en la conducción de sus vidas. De ahí que sea muy importante, como varios pensadores lo reiteran, el vínculo que cada individuo tenga con sus grupos, la relación libre que cada persona tenga con su comunidad, colectivo o sociedad, pues ese es el eje de una con-vivencia sana y, como tal, se tiene que salvaguardar: "La libertad para determinar nuestras lealtades y prioridades entre los diferentes grupos a los que pertenecemos es peculiarmente importante, $y$ tenemos razones para reconocerla, valorarla y defenderla" ${ }^{18}$.

La libertad como eje de la organización social sigue presente, pero en este caso en tanto acción libre de individuos que pertenecen a diferentes grupos y que deciden sus particulares relaciones con estos. Desde esta línea argumentativa, el ser humano, sin negar su carácter racional, es, ante todo, un ser de grupos, una persona que conforma varios y distintos grupos y que, en razón de esto, reclama consideración y respeto por sus vínculos, sus puntos de vista y sus razones. A partir de esto, el ser humano también pide reconocimiento, el cual también se interpreta como un dejar ser y hacer libre al individuo en atención a los grupos con los que se vincula. Esto es importante porque tales grupos evidencian perspectivas (de vida) y, de este modo, ayudan a perfilar identidades. La relación con grupos es determinante para el ser humano, por eso lo que mínimamente se espera es un respeto por los grupos en los que se sitúa cada persona y por la forma como entabla relación con cada uno de ellos. Se trata, pues, de dejar fluir, en principio, libremente tales vínculos, evitando interferir en los mismos, siendo conscientes de las consecuencias negativas que lo contrario puede acarrear. Recordemos que no hay un solo modo de ser, hay muchos, y la afirmación y realización de uno de ellos supone e implica lo mismo para los demás. Por eso habíamos afirmado líneas atrás la carga normativa de la ética, su concepción como un modo de ser que comprende un deber ser. Este deber ser se asienta en la relación con el otro, sea este 
entendido prioritariamente como un ser racional con derechos universales o como una persona que tiene una historia e identidad gracias a su pertenencia a distintos grupos. En suma, la ética refiere una manera de ser y vivir sujeta a límites determinados por los otros y a la consideración y respeto que se les debe: "La ética (...) dice aproximadamente: 'Piensa que los otros están ahí. Empieza por no hacerles lo que no te gustaría que te hiciesen a ti'. Antes de amar, antes incluso de ayudar, se trata de no perjudicar, de no hacer daño"69.

Desde una comprensión básica e inicial, la ética se vincula con el no daño, esto es, la ética se relaciona con el no interferir en la vida del otro, con el no impedir, en principio, que las maneras de ser y hacer se den, acontezcan, sabiendo que lo contrario puede dar lugar a fuertes obstáculos para la realización de cada persona y para una sana y armónica con-vivencia. Cada individuo es, en cierta medida, en atención a la percepción de los demás individuos, en atención a lo que sienten y piensan los otros respecto de él, y ello condiciona, en determinado grado, la formación de toda identidad. Ningún individuo se puede sustraer de esto, esto va más allá de gremios profesionales, clases sociales, ocupaciones laborales y comunidades ancestrales. Tanto el abogado, el campesino, el rico, el pobre, el empresario o el empleado (o, por ejemplo en nuestro país, el limeño o el asháninka) se pronuncia y necesita ser escuchado por los demás, pues dicha recepción se expresa, a la larga, en sensaciones e ideas que influyen en la afirmación y en la consolidación de un modo de ser (libre).

Se evidencia nuevamente, en la posibilidad de un actuar libre, el lugar y la importancia del otro con el que se vive. Así, la libertad se vuelve a plantear en términos del reconocimiento; por eso, Isaiah Berlin considera que "La falta de libertad de la que se quejan muchos hombres y grupos no es otra cosa, con frecuencia, que falta de reconocimiento adecuado"70. Si uno no se siente reconocido, siente mermada su libertad, siente que su actuar no se va a desplegar de manera libre, sino al contrario, que se va a enfrentar a fuertes obstáculos. Entonces se impone necesariamente una con-vivencia sostenida en la relación entre individuos que se miran, se escuchan, se comprenden y se respetan mutuamente, individuos que por no formar parte de los mismos

69 Droit, Roger-Pol, La ética explicada a todo el mundo, Barcelona/Buenos Aires/México D.F.: Paidós, 2010, p. 37.

70 Berlin, Isaiah, Sobre la libertad, Madrid: Alianza Editorial, 2009, pp. 238-239. 
grupos o colectivos no dejan de reconocerse. Ese es el reto de la convivencia, esa es la tarea de la vida con los otros: tratar de armonizar lo que se es, las distintas maneras en que se es, con la exigencia de considerar y de respetar a los otros, pues cada uno de estos es, finalmente, un ser (humano) con diferentes modos de ser. Cada individuo quiere ser y hacer libremente, pero enseguida tiene que ajustar su comportamiento en atención a los otros, esto es, debe escuchar ciertos mensajes y seguir determinadas pautas que su situación le exige. En eso consiste ser, es decir, poder ser de una o varias maneras, sin desconocer lo que se debe hacer. La ética tiene, en definitiva, un carácter dilemático: "El grado de libertad de un hombre o de un pueblo para elegir vivir como desee debe sopesarse frente a las demandas de otros muchos valores, de los cuales la igualdad, la justicia, la felicidad, la seguridad y el orden público quizá sean los ejemplos más obvios. Por esta razón, la libertad de elección no puede ser ilimitada"7!.

Nuestro modo o modos de ser tienen frente a sí requisitos fundamentales de la vida social, por eso se trata de conjugar de la mejor manera lo que uno es o busca ser con lo que debe ser y hacer. Esto traza un trayecto difícil para la vida de todo ser humano consciente de las características del escenario en el que tiene que actuar. Queremos actuar haciendo elecciones y tomando decisiones libres, pero sabiendo que los demás también están en esta misma situación y merecen igualmente consideración; sabiendo además que de la conciencia de esto y de su consecuencia al actuar depende, en un importante grado, el orden en el espacio que muchos compartimos. Esto caracteriza un escenario difícil pero, con todo, el mejor posible, pues si la perspectiva del respecto se pierde, la situación se agrava. Es el caso del individuo que quiere sery hacer libremente perdiendo de vista la realidad enorme y compleja que lo comprehende, sin tener conciencia de las circunstancias que lo engloban y que lo ponen frente a otras personas con deseos, intereses y metas por alcanzar también. Y si bien la realidad puede parecerle clara, fluida y sin contratiempos al individuo que no termina de ubicarse en ella, en el fondo sucede todo lo contrario, pues este, con su visión de las cosas, termina simplificándola, tergiversándola y, muchas veces, minimizando a los demás individuos que la conforman. Lo grave de esta situación se evidencia cuando la perspectiva de la 
realidad que se ha descrito se multiplica hasta "normalizarse", hasta tornarse una perspectiva común a muchos, pues con ello se consolida una relación con el escenario de con-vivencia, en general, y con los seres humanos con los que se con-vive, en particular, que puede hacer posible el daño, justificándolo y, en el peor de los casos, fomentándolo.

El dilema inherente a la ética entre el sery el deber ser es el dilema que en cierto grado y en cierta forma está siempre latente en la vida de todo ser humano en tanto individuo que vive con otros. Lo complejo del dilema mencionado es lo difícil de ser como se quiere ser y, a la vez, actuar como debe ser. Es difícil armonizar los mensajes que recibo de mis grupos, las licencias y las exigencias que estos me transmiten, con formas particulares de ser asentadas principalmente en reflexiones o en sensaciones y sentimientos propios. Con todo, hay que hacerse cargo de ello, hay que aceptar el reto, pues son las condiciones de la vida social y los requisitos para alcanzar y sostener un orden en esta. Dicho reto no es nuevo, siempre estuvo presente en las distintas etapas de la historia humana; quizá ahora se muestra más complejo y apremiante, pues vivimos en sociedades más grandes, con muchos habitantes, con estructuras cuya organización es más compleja, en donde las comunidades o colectivos de diversa índole se multiplican y son cada vez más visibles. La disyuntiva sigue transitando entre simple y libremente ser, y regular el vivir en atención a lo que se debe ser (con todos los matices que se pueden encontrar entre estos puntos). Lo conflictivo sigue asentándose en atender a las líneas de acción históricas, temporales y culturales aprendidas o en buscar trascenderlas sujetándose a principios de acción que el individuo postula independientemente gracias a su reflexión. Lo difícil es entender la ética como un modo de ser que comprende un deber ser y ver cómo esto se puede expresar en la vida misma. Se trata de detenernos en el comportamiento moral y determinar los factores en él dirimentes, sabiendo que una ética sujeta estrictamente a lineamientos histórico-tradicionales, que no le otorga un lugar importante al individuo autónomo, está perdiendo vigencia. Pero sabiendo, a su vez, que una moral sustraída de toda influencia histórica y cultural, asentada en el pensamiento único y singular de un individuo es, por lo menos, difícil de imaginar 
en su aplicación real. Esto explica la desorientación que muchos identifican en la situación actual de la ética ${ }^{72}$.

¿Cómo se puede ser de una determinada manera sin desatender a un deber ser? ¿Qué tan real es la noción de pensamiento único, individual y estrictamente autónomo? ¿Cuándo la "formación" que parte de nuestros gruposy respectivas realidades restringe y limita nuestro ser y proceder particular? Estas son preguntas de difícil resolución que conducen, sin duda, a una extensa y compleja reflexión que ha de considerar muchos elementos tangibles si quiere recalar, por lo menos, en ciertas conclusiones verosímiles, y no identificarse solamente con una especulación interesante pero alejada de requerimientos reales inscritos en el acontecer cotidiano e incesante de la vida de los seres humanos. Hay hechos ineludibles a considerar que marcan el pensar y el actuar de las personas; la participación de estas en grandes sociedades, en comunidades o en colectivos particulares es uno de ellos. Y en relación con lo anterior, el hecho de que en estas sociedades, comunidades o colectivos siempre hay otros que nos están confrontando es también una cuestión contundente. Hay otros que son cercanos, en tanto mantenemos una relación más estrecha hablando constantemente con ellos, y otros que son más lejanos pues nuestro contacto con ellos no es inmediato, sino que está mediado por otras cosas, pero que, con todo, están también ahí para ser reconocidos. Estos hechos le otorgan un carácter particular a la con-vivencia humana, imprimiéndole cierta lógica en la que lo recurrente es, entre otras cosas, la exigencia recíproca y la presión asociada a ella.

Estar y vivir con otros bajo un modo de ser (y deber ser) que regula las relaciones es participar de una moral y reforzarla, es vivir con otros aceptando ciertos presupuestos y acuerdos-no necesariamente explícitos-y asumiendo las exigencias y consecuencias que de ellos se derivan. Es adoptar un modo de vida regulado por exigencias que parten de los otros con respecto a nuestro actuar y que también parten de nosotros con respecto al comportamiento de ellos. Estas exigencias se enlazan con sentimientos aprendidos $y$, por eso, reforzados, cuya presencia constante prueba que hay un orden de cosas que respetar. Así pues, la indignación que sienten unos por la actuación de otros 
y el consecuente sentimiento de culpa de estos a partir de aquella reacción, evidencia una lógica normativa en la con-vivencia que, si bien no se expresa en leyes objetivas, necesarias y universales, tiene en la presión social una prueba inobjetable de su existencia ${ }^{73}$. Sin embargo, como se señaló antes, dicha organización o lógica normativa, así como es objeto de asentimiento, también es materia de cuestionamiento, en atención a la dificultad-siempre presente- de conjugar la forma particular de ser y el orden general de ese todo que nos forma y vigila en tanto que nos comprehende. Tal dificultad es diversa y gradual, debido a que está en función de, entre otras cosas, la particularidad de cada uno de los espacios en los que actuamos, en mayor o menor medida, permanentemente; espacios que hemos comprendido como la comunidad, el colectivo y la sociedad. Siendo estos, en general, espacios de con-vivencia, también son escenarios singulares que acompañan y exigen a los individuos de maneras distintas. De ahí que la situación de tensión entre el ser (particular) y el deber ser (general) se pueda percibir como algo llevadero o como algo difícil de tolerar, pues el desacuerdo en la comunidad quizá es manejable en comparación con la contraposición de perspectivas en la sociedad: “(...) icómo es posible el autogobierno de nuestras vidas cuando habitamos lo público, y en ese espacio es donde somos gobernados políticamente por otros: por las mayorías que votan, por las instituciones que se crearon en algún momento anterior, casi siempre antes de nacer nosotros, y que son regidas por personas que están lejanas y nos son lejanas? ¿No es, sencillamente, una ecuación imposible? ¿O serán las condiciones para resolverla demasiado ideales, demasiado inasequibles?"74.

¿Cómo ser auténticamente en una realidad que, de manera inexorable, se pronuncia sobre lo que se debe ser y hacer?, icómo (buscar) estar bien individualmente en un escenario que compartimos con otros y en el que, por ende, debemos atender a estos? En otras palabras, icómo ser y actuar libremente, sin dejar de reconocer a los otros? Tales preguntas delinean la discusión de fondo en la ética, ellas perfilan uno de los dilemas que están inscritos en esta, y así la muestran como una gran (importante) palabra, en tanto significa el gran reto en la vida con los otros. Abordar la ética es, a la larga, confrontarnos con las anteriores interrogantes, pues son cuestiones 
siempre latentes que se hacen más visibles en momentos críticos en los que, precisamente, el ser humano se da cuenta de lo complejo que puede resultar ser (como se quiere), dada su condición de estar con otros y la exigencia de siempre atender a estos. Tal es la condición humana que no hay que lamentar, sino reconocer y no perder de vista, y lo que es más difícil, pensar siempre, sobre todo cuando se actúa, cuando se vive. Pues estamos junto a otros y vivimos con estos, esa es nuestra morada, nuestro ethos. 